\title{
Assembling an isomer grid: the isomorphous 4-, 3- and 2-fluoro- $N^{\prime}$-(4-pyridyl)benzamides
}

\author{
Katie Donnelly, John F. Gallagher and Alan J. Lough
}

Acta Cryst. (2008). C64, o335-0340

Copyright (C) International Union of Crystallography

Author(s) of this paper may load this reprint on their own web site or institutional repository provided that this cover page is retained. Republication of this article or its storage in electronic databases other than as specified above is not permitted without prior permission in writing from the IUCr.

For further information see http://journals.iucr.org/services/authorrights.html

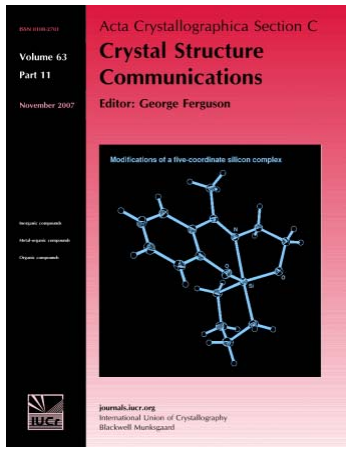

Acta Crystallographica Section C: Crystal Structure Communications specializes in the rapid dissemination of high-quality studies of crystal and molecular structures of interest in fields such as chemistry, biochemistry, mineralogy, pharmacology, physics and materials science. The numerical and text descriptions of each structure are submitted to the journal electronically as a Crystallographic Information File (CIF) and are checked and typeset automatically prior to peer review. The journal is well known for its high standards of structural reliability and presentation. Section $C$ publishes approximately 1000 structures per year; readers have access to an archive that includes high-quality structural data for over 10000 compounds.

Crystallography Journals Online is available from journals.iucr.org 
Acta Crystallographica Section C

Crystal Structure

Communications

ISSN 0108-2701

\section{Assembling an isomer grid: the isomorphous 4-, 3- and 2-fluoro- $N^{\prime}$-(4-pyridyl)benzamides}

\author{
Katie Donnelly, John F. Gallagher ${ }^{a *}$ and Alan J. Lough

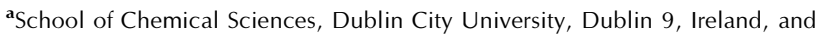 \\ ${ }^{\mathbf{b}}$ Department of Chemistry, 80 St George Street, University of Toronto, Ontario, \\ Canada M5S $3 \mathrm{H} 6$ \\ Correspondence e-mail: john.gallagher@dcu.ie
}

Received 22 April 2008

Accepted 25 April 2008

Online 21 May 2008

The three title isomers, 4-, (I), 3-, (II), and 2-fluoro- $N^{\prime}-(4-$ pyridyl)benzamide, (III), all $\mathrm{C}_{12} \mathrm{H}_{9} \mathrm{FN}_{2} \mathrm{O}$, crystallize in the $P 2_{1} / c$ space group (No. 14 ) with similar unit-cell parameters and are isomorphous and isostructural at the primary hydrogen-bonding level. An intramolecular $\mathrm{C}-\mathrm{H} \cdots \mathrm{O}=\mathrm{C}$ interaction is present in all three isomers $[\mathrm{C} \cdots \mathrm{O}=$ 2.8681 (17)-2.884 (2) $\AA$ and $\left.\mathrm{C}-\mathrm{H} \cdots \mathrm{O} 117-118^{\circ}\right]$, with an additional $\mathrm{N}-\mathrm{H} \cdots \mathrm{F}[\mathrm{N} \cdots \mathrm{F}=2.7544(15) \AA]$ interaction in (III). Intermolecular amide-pyridine $\mathrm{N}-\mathrm{H} \cdots \mathrm{N}$ hydrogen bonds link molecules into one-dimensional zigzag chains [graph set $C(6)$ ] along the [010] direction as the primary hydrogen bond $[\mathrm{N} \cdots \mathrm{N}=3.022$ (2), 3.049 (2) and 3.0213 (17) $\AA$ ]. These are augmented in (I) by $\mathrm{C}-\mathrm{H} \cdots \pi$ (arene) and cyclic $\mathrm{C}-\mathrm{F} \cdots \pi$ (arene) contacts about inversion centres, in (II) by $\mathrm{C}-\mathrm{F} \cdots \mathrm{F}-\mathrm{C}$ interactions $[\mathrm{C} \cdots \mathrm{F}=3.037$ (2) $\AA$ ] and weaker $\mathrm{C}-\mathrm{H} \cdots \pi($ arene $) / \mathrm{C}-\mathrm{H} \cdots \mathrm{F}$ contacts, and in (III) by $\mathrm{C}-$ $\mathrm{H} \cdots \pi$ (arene) and $\mathrm{C}=\mathrm{O} \cdots \mathrm{O}=\mathrm{C}$ interactions, linking the alternating chains into two-dimensional sheets. Typical amide $\mathrm{N}-\mathrm{H} \cdots \mathrm{O}=\mathrm{C}$ hydrogen bonds [as $C(4)$ chains] are not present $[\mathrm{N} \cdots \mathrm{O}=3.438$ (2) $\AA$ in (I), 3.562 (2) $\AA$ in (II) and 3.7854 (16) $\AA$ in (III)]; the $\mathrm{C}=\mathrm{O}$ group is effectively shielded and only participates in weaker interactions/contacts. This series is unusual as the three isomers are isomorphous (having similar unit-cell parameters, packing and alignment), but they differ in their interactions and contacts at the secondary level.

\section{Comment}

Structural systematics of small molecules has undergone an enormous change in the past decade with technical advances in the ability to collect and analyse many crystal structures within a short timeframe. Of interest in this research are studies on polymorphism, pseudopolymorphism and isomers and their impact on the development of new materials (Gelbrich et al., 2007; Wardell et al., 2007, 2008). As progress in predicting crystal structures continues to greatly expand knowledge from first principles, it is the drive amongst synthetic chemists and chemical crystallographers to assemble comprehensive sets of crystal structure data that will provide a continual challenge to but also aid in the ongoing development of this predictive science (Day et al., 2005). A relatively facile method of obtaining extensive and related crystal structure data sets is the assembly of isomer grids and subsequent grid expansion (with polymorphs of individual compounds), using variable solvent content and cocrystallizations to generate pseudopolymorphs, and using variabletemperature studies to analyse potential phase changes. We report here the molecular and crystal structures of the 4-, 3and 2-fluoro- $N^{\prime}$-(4-pyridyl)benzamide isomers, (I)-(III) (Figs. 1-3), obtained from the reaction of 4-, 3- and 2-fluorobenzoyl chloride and 4-aminopyridine. This is the first in a series of studies of isomers and model compounds for the assembly of an isomer grid.

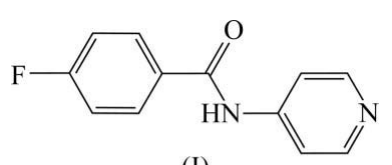

(I)

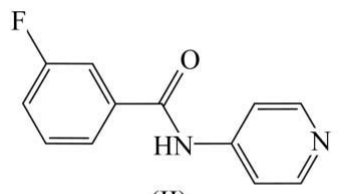

(II)

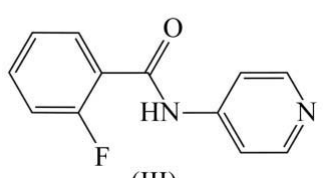

(III)

The geometric data (bond lengths and angles) in (I)-(III) are normal and are not discussed except for some comparisons and with reference to the hydrogen bonding. It is of note that the $\mathrm{C}-\mathrm{F}$ bond lengths differ markedly $[1.365$ (2) $\AA$ in (I),

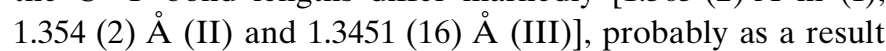
of the secondary hydrogen bonding (see below). The F atom is located cisoid to the $\mathrm{C}=\mathrm{O}$ group in (II) but transoid in (III).

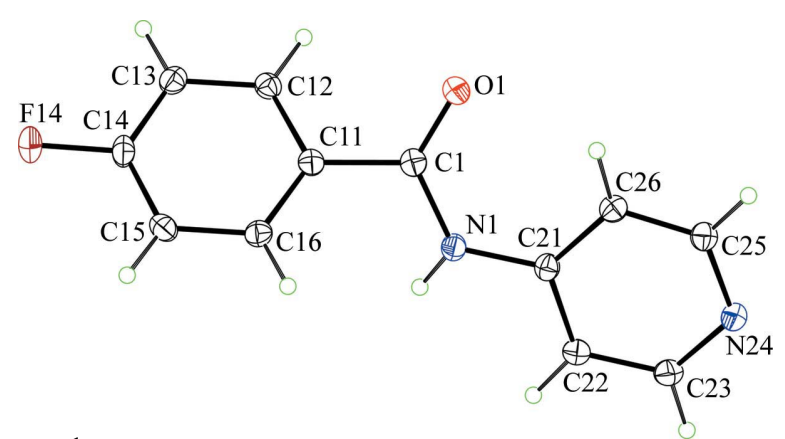

Figure 1

A view of (I), showing the atomic numbering scheme. Displacement ellipsoids are drawn at the $30 \%$ probability level. 
No noticeable trends are evident from analysis of the bondangle data. The defining feature of the molecular conformation is the benzene-pyridine dihedral angle, which is mutually oriented at $51.95(6)^{\circ}$ in (I), $48.75(6)^{\circ}$ in (II) and $46.34(5)^{\circ}$ (III) (see the torsion angles in Tables 1, 3 and 5); pyramida-

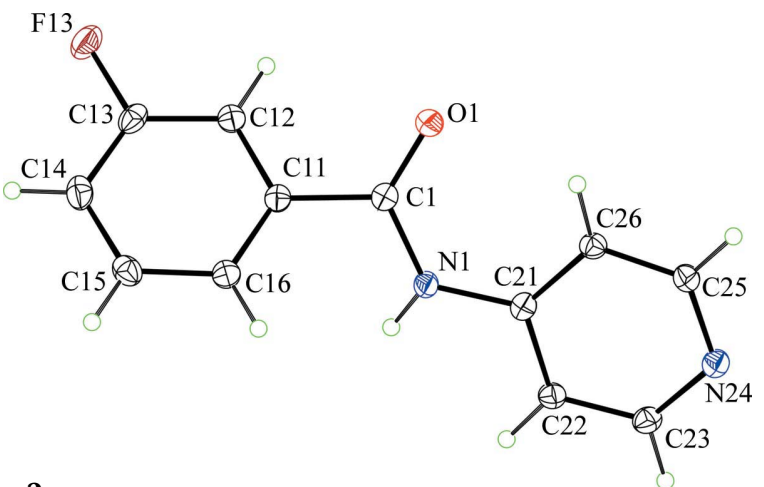

Figure 2

A view of (II), showing the atomic numbering scheme. Displacement ellipsoids are drawn at the $30 \%$ probability level.

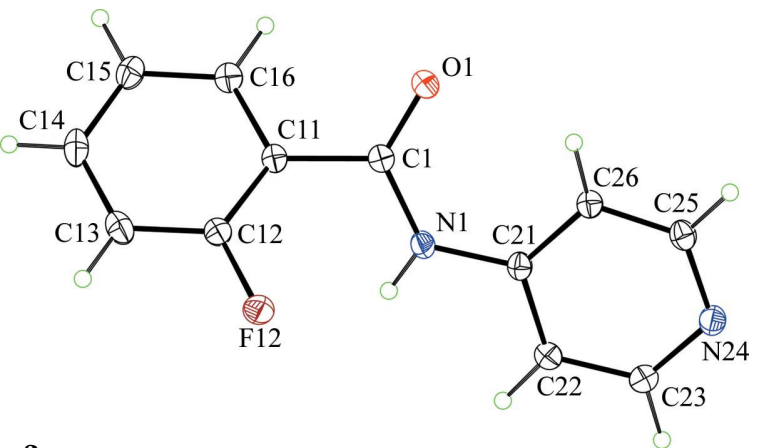

Figure 3

A view of (III), showing the atomic numbering scheme. Displacement ellipsoids are drawn at the $30 \%$ probability level.

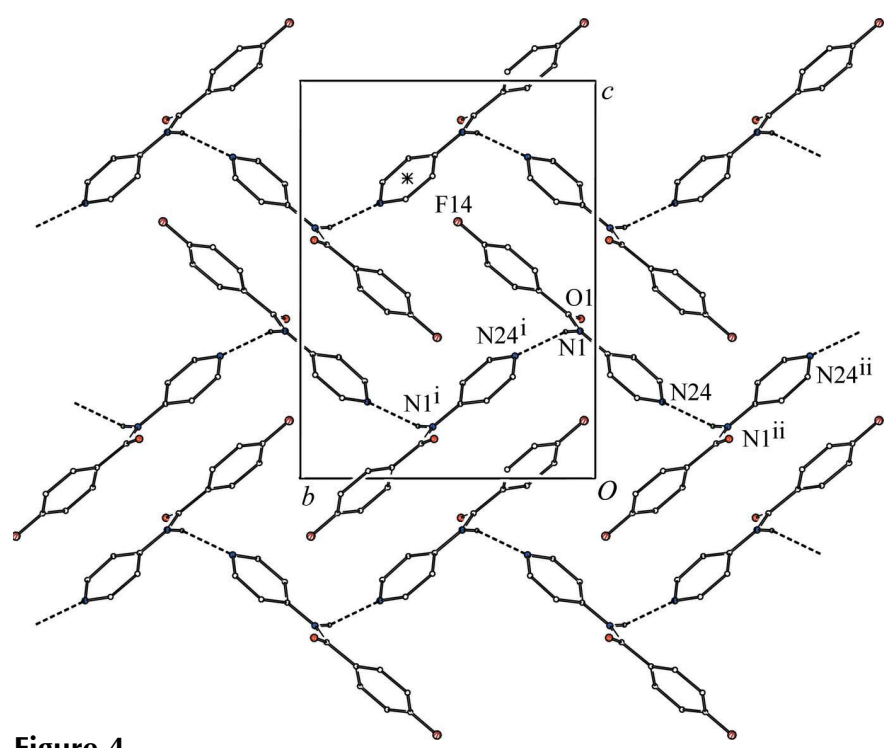

The primary $\mathrm{N}-\mathrm{H} \cdots \mathrm{N}$ interactions in (I); $\mathrm{H}$ atoms not involved in hydrogen bonding have been omitted for clarity. The pyridine ring at position $\left(x,-y+\frac{1}{2}, z+\frac{1}{2}\right)$ [labelled with an asterisk (*)] participates in an F $\cdots \pi$ (arene) contact. [Symmetry codes: (i) $-x+1, y+\frac{1}{2},-z+\frac{1}{2}$; (ii) $-x+1, y-\frac{1}{2},-z+\frac{1}{2}$.] lization is not discernible at the amide N1 atom, with angles summing to within $3^{\circ}$ of $360^{\circ}$.

For molecular comparisons, the asymmetric units have been chosen to be close to the origin and with the molecular axes aligned in similar orientations. A key feature in all three isomers is the intramolecular interaction between atoms C26 and $\mathrm{O} 1$ [with an $S(6)$ motif], with $\mathrm{C} 26 \cdots \mathrm{O} 1$ in the narrow range of $2.87 \pm 0.01 \AA$. In (III), there is an additional intramolecular $\mathrm{N}-\mathrm{H} \cdots \mathrm{F}$ interaction $[\mathrm{N} \cdots \mathrm{F}=2.7544(15) \AA]$ between the ortho-F and amide NH atoms (see Tables 2, 4 and 6).

The defining and primary intermolecular interaction in all three systems is the amide-pyridine $\mathrm{N}-\mathrm{H} \cdots \mathrm{N}$ hydrogen bond that links molecules into one-dimensional zigzag chains [graph set $C(6)$ ] along the [010] direction [with $\mathrm{N} \cdots \mathrm{N}$ distances of 3.022 (2), 3.049 (2) and 3.0213 (17) Å].

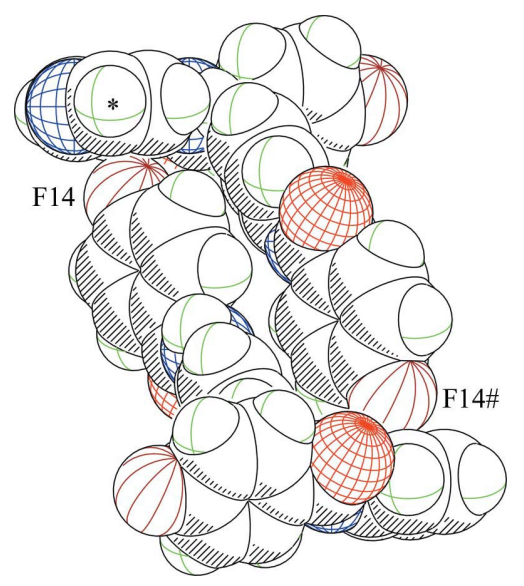

Figure 5

A view of the packing and $\mathrm{C}-\mathrm{F} \cdots \pi$ (arene) contacts in (I), with atoms depicted as their van der Waals spheres. The hash symbol (\#) denotes an inversion-symmetry-related molecule at position $(-x+2,-y,-z+1)$. The asterisk (*) indicates the pyridine ring defined in Fig. 4.

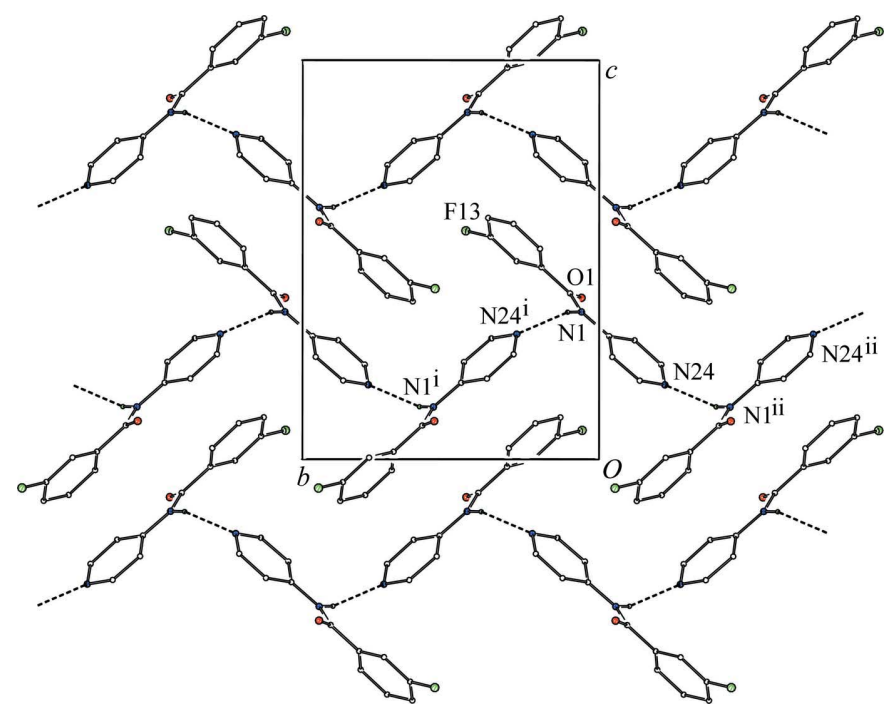

Figure 6

The primary $\mathrm{N}-\mathrm{H} \cdots \mathrm{N}$ interactions in (II); $\mathrm{H}$ atoms not involved in these interactions have been omitted. [Symmetry codes: (i) $-x+1, y+\frac{1}{2},-z+\frac{1}{2}$; (ii) $-x+1, y-\frac{1}{2},-z+\frac{1}{2}$.] 
In (I), weaker $\mathrm{C}-\mathrm{H} \cdots \pi$ (arene) and $\mathrm{C}-\mathrm{F} \cdots \pi$ (arene) contacts (about inversion centres) link alternating chains into a two-dimensional sheet [Table 2; F14 $\cdots \mathrm{C} 21^{\mathrm{v}}=3.091$ (2) $\AA$; symmetry code: (v) $\left.x,-y+\frac{1}{2}, z+\frac{1}{2}\right]$, with each chain dovetailing into its two nearest neighbouring chains aligned in the opposite direction along [010] (Figs. 4 and 5). There are no $\mathrm{C}-\mathrm{H} \cdots \mathrm{F}-\mathrm{C}$ or $\mathrm{C}-\mathrm{F} \cdots \mathrm{F}-\mathrm{C}$ interactions.

In (II), the primary interaction is augmented by three weaker $\mathrm{C}-\mathrm{H} \cdots \pi$ (arene) contacts per molecule, linking the alternating chains into a two-dimensional sheet (Table 4); each chain dovetails as in (I) (Figs. 6 and 7). Instead of C-F... $\pi$ (arene) facial contacts as for (I), the location of the $\mathrm{F}$ atom provides alternative interaction sites. The most notable is the $\mathrm{C} 13-\mathrm{F} 13 \cdots(\mathrm{F} 13-\mathrm{C} 13)^{\mathrm{vi}}$ contact about an inversion centre $\left[\mathrm{F} 13 \cdots \mathrm{C} 13^{\mathrm{vi}}=3.037\right.$ (2) $\AA$ and F13 $\cdots \mathrm{F} 13^{\mathrm{vi}}=3.1180$ (17) $\AA$; symmetry code: (vi) $-x+2,-y+1,-z+1$ ], with an offset $\mathrm{C}_{6}$ interplanar separation of $3.01 \AA$. Two weak $\mathrm{C}-\mathrm{H} \cdots \mathrm{F}$ contacts are also present $(\mathrm{H} \cdots \mathrm{F}=2.65 \AA$, and $\mathrm{C}-\mathrm{H} \cdots \mathrm{F}=115$ and $117^{\circ}$ ).

In (III), the one-dimensional chains are further linked by $\mathrm{C}-\mathrm{H} \cdots \pi$ (arene) contacts into two-dimensional sheets (Figs. 8 and 9, and Table 6). Molecules are also linked via antiparallel $\mathrm{C}=\mathrm{O} \cdots \mathrm{O}=\mathrm{C}$ interactions (Allen et al., 1998) aligned about inversion centres, with $\mathrm{C} 1$...OO ${ }^{\mathrm{iii}}$ distances of 3.1919 (16) $\AA$ [symmetry code: (iii) $-x+2,-y,-z+1$ ].

Usually benzamides form intermolecular $\mathrm{N}-\mathrm{H} \cdots \mathrm{O}=\mathrm{C}$ interactions [with a $C(4)$ graph set] as their primary interaction in the absence of other competing strong donors/ acceptors (Gowda et al., 2008). In (I)-(III), the amide NH group and pyridine $\mathrm{N}$-atom acceptor form amide-pyridine $\mathrm{N}-\mathrm{H} \cdots \mathrm{N}$ chains [graph set $C(6)$ ] as the primary interaction, thus preventing the formation of standard $C(4)$ chains. In (I), the closest intermolecular $\mathrm{N} \cdots \mathrm{O}$ contact $[\mathrm{N} 1 \cdots \mathrm{O} 1(x-1, y$, $z)=3.438$ (2) $\AA$ along [100]; $\mathrm{N}-\mathrm{H} \cdots \mathrm{O}=125^{\circ}$ ] is $0.4 \AA$ longer and $\sim 20^{\circ}$ smaller in angle than the amide-pyridine $\mathrm{N}-\mathrm{H} \cdots \mathrm{N}$ interaction. For (II), the closest intermolecular $\mathrm{N}$. . O contact $[\mathrm{N} 1 \cdots \mathrm{O} 1(x-1, y, z)=3.562(2) \AA$ along [100]; $\mathrm{N}-\mathrm{H} \cdots \mathrm{O}=$ $130^{\circ}$ ] is $0.5 \AA$ longer and ca $18^{\circ}$ smaller in angle than the amide-pyridine $\mathrm{N}-\mathrm{H} \cdots \mathrm{N}$ interaction, while in (III) the
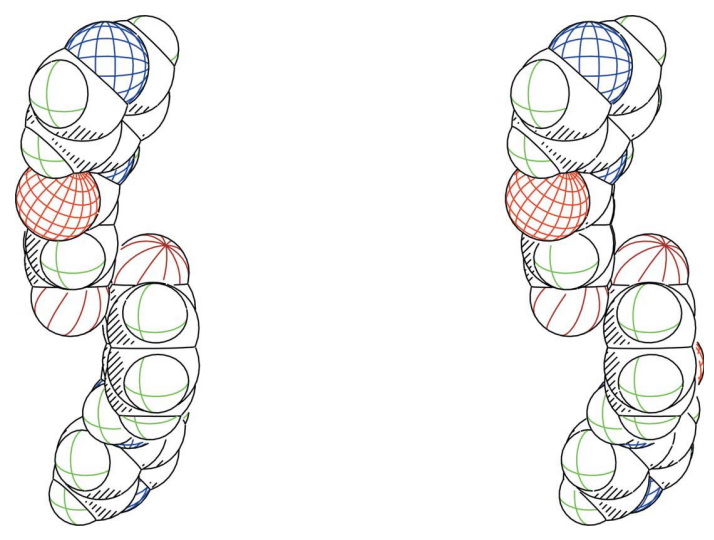

Figure 7

A stereoview of the $\mathrm{C}-\mathrm{F} \cdots \mathrm{F}-\mathrm{C}$ contacts in (II), with atoms depicted as their van der Waals spheres. closest intermolecular $\mathrm{N} \cdots \mathrm{O}$ contact $[\mathrm{N} 1 \cdots \mathrm{O} 1(x-1, y, z)=$ 3.7854 (16) $\AA$ along [100]; $\mathrm{N}-\mathrm{H} \cdots \mathrm{O}=135^{\circ}$ ] is $\sim 0.75 \AA$ longer and $\mathrm{ca} 4^{\circ}$ smaller in angle than the amide-pyridine $\mathrm{N}-$ $\mathrm{H} \cdot \mathrm{N}$ interaction.

All three isomers have similar unit-cell parameters in the monoclinic space group $P 2_{1} / c$ (No. 14), and have similar packing and hydrogen-bond motifs (similar at the primary level but different at the secondary interaction levels), and they are isomorphous (in the strict interpretation of the definition, as the atom-site coordinates coincide) in the solid state. The close similarity in the packing of all three structures is relatively easy to visualize (Figs. 4, 6 and 8 display three zigzag chains with the unit-cell axes). For comparison, the unit-cell similarity index, $\Pi$, is less than 0.015 for the (I)/(II)/(III) pairs (Kálmán et al., 1993); homeostructural crystal pairs and packing 'similarities' generated by substituent migration in dichloroanilines have also been discussed by Dou et al. (1993) and Kálmán et al. (1993).

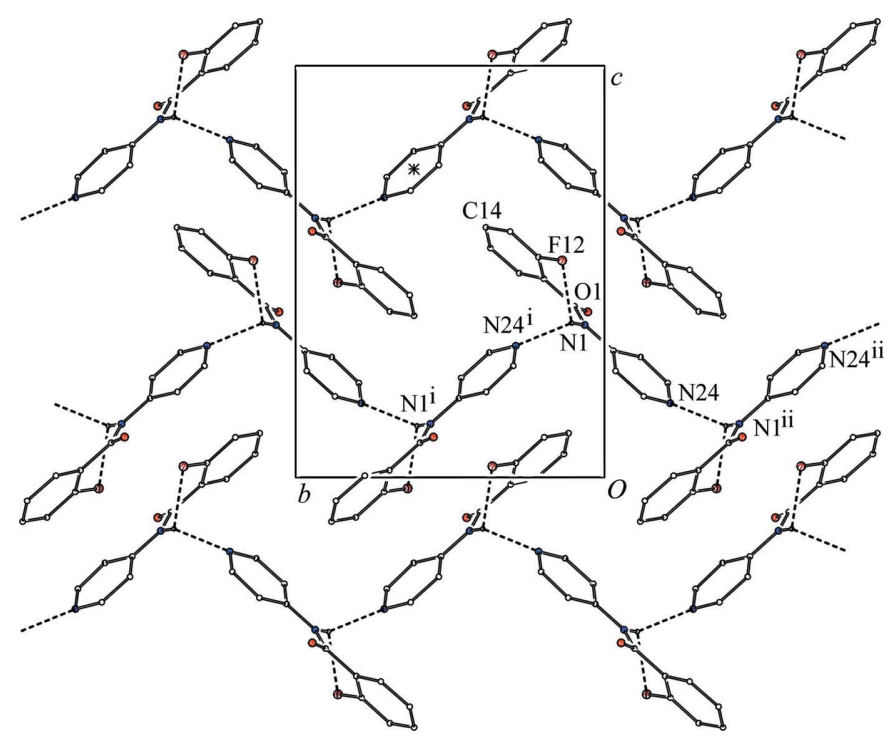

Figure 8

The primary $\mathrm{N}-\mathrm{H} \cdots \mathrm{N}$ interactions in (III); $\mathrm{H}$ atoms not involved in these interactions have been omitted. The asterisk $(*)$ indicates the symmetry-related pyridine ring at $\left(x, y-\frac{1}{2}, z+\frac{1}{2}\right)$. [Symmetry codes: (i) $-x+1, y+\frac{1}{2},-z+\frac{1}{2}$; (ii) $-x+1, y-\frac{1}{2},-z+\frac{1}{2}$.]

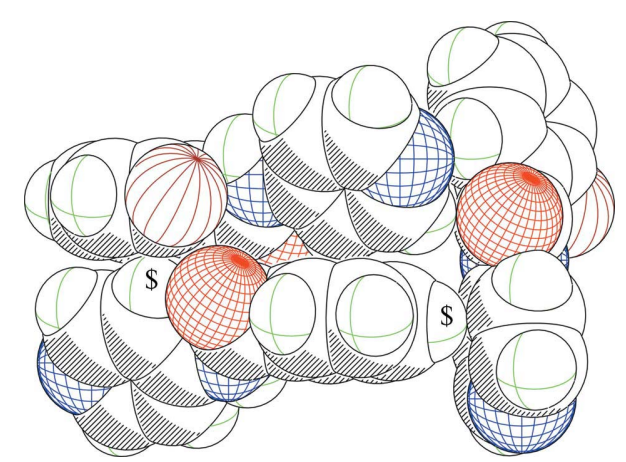

Figure 9

Two $\mathrm{C}-\mathrm{H} \cdots \pi($ arene) contacts in (III), with atoms depicted as their van der Waals spheres; the dollar symbols (\$) indicate the arene rings. 
The replacement of an $\mathrm{F}$ atom on the $\mathrm{C}_{6}$ ring involves isosteric replacement of an $\mathrm{H}$ atom. The change of the $\mathrm{F}$-atom site from para to meta to ortho only generates different secondary interactions (as can be reasoned), as primary amide-pyridine $\mathrm{N}-\mathrm{H} \cdots \mathrm{N}$ interactions define the principal aggregation mode. Chopra \& Row (2008) have recently reported a comprehensive study on a series of mono- and difluorobenzanilides [DC3-DC1, hereafter denoted DC(3-1); see scheme below]. The DC(3-1) structures correspond to (I)(III) by replacement of the pyridine $\mathrm{N}$ atom by a $\mathrm{CH}$ group. The DC(3-1) packing is dominated by standard $\mathrm{N}-$ $\mathrm{H} \cdots \mathrm{O}=\mathrm{C}$ hydrogen bonds $[3.165$ (4)-3.254 (4) $\AA$ ], the intramolecular $\mathrm{C}_{6} / \mathrm{C}_{6}$ plane angles range from 23.0 (3) to $32.9(1)^{\circ}$, and the $\mathrm{N}$...O distances are at least $0.2 \AA$ shorter than the corresponding data in (I)-(III) (Chopra \& Row, 2008). In these fluorobenzanilides, alteration of the packing modes is observed as the F-atom position changes through para to meta to ortho. In related work, Gowda et al. (2008) have also reported a series of similar substituted alkyl- and chlorophenylbenzamides. Wardell et al. (2008) have also recently reported an extensive series of $\mathrm{N}$-arylpyrazinecarboxamides; however, the authors state that isomeric compounds in this series 'show little resemblance in the supramolecular behaviour beyond crystallization in the same space group'. Clearly, more expanded isomer series are needed for detailed structural and computational comparisons.

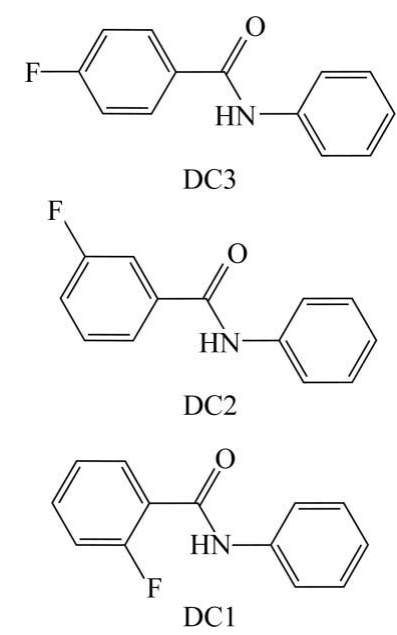

Melting-point analysis and correlations with structural properties have been reviewed for organic compounds by several groups recently (Slovokhotov et al., 2004; Gilbert, 2007). Researchers have noted that more symmetrical structural isomers almost always possess higher melting points than their less symmetric analogues (Gilbert, 2007). Compounds (I)-(III) can only possess mirror symmetry $\left(C_{s}\right)$ as the highest possible molecular symmetry in the appropriate conformation (solution/gas phase), but for (III) this is unlikely on steric grounds $(\mathrm{N}-\mathrm{H} \cdots \mathrm{F}$ steric hindrance). There is a distinct trend from (I) (456-459 K) to (II) (443-446 K) to (III) (396-398 K).
The overall packing is very similar at the primary amidepyridine $\mathrm{N}-\mathrm{H} \cdots \mathrm{N}$ level and reasonably comparable (in terms of the number and type of weak interactions) at the secondary level.

An explanation for this melting-point trend may be the distinct $\mathrm{N}-\mathrm{H} \cdots \mathrm{O}=\mathrm{C}$ distance differences of 3.438 (2), 3.562 (2) and 3.7854 (16) $\AA$ in (I)-(III), resulting from the molecular packing; the packing may be such as to prevent the potential (though temporary) formation of amide-amide $\mathrm{N}-$ $\mathrm{H} \cdots \mathrm{O}=\mathrm{C}$ interactions as the amide-pyridine $\mathrm{N}-\mathrm{H} \cdots \mathrm{N}$ interactions weaken on heating. In (I), without the steric demand of an ortho-F atom, the weakening of the amidepyridine $\mathrm{N}-\mathrm{H} \cdots \mathrm{N}$ hydrogen bond may be compensated for and offset by some increasing but temporary $\mathrm{N}-$ $\mathrm{H} \cdots \mathrm{O}=\mathrm{C}$ interaction, resulting in the observed melting-point trend.

The present series is unusual as the three isomers are isomorphous (having similar unit-cell parameters, packing and alignment), but differ in $\mathrm{F} / \mathrm{H}$ peripheral atom-site position and in their interactions and contacts at the secondary level.

\section{Experimental}

Compound (I) has been synthesized previously both as (i) a labelled [carbonyl $-{ }^{11} \mathrm{C}$ ]amide via a one-pot in situ reaction of the amine coupled with $\left[{ }^{11} \mathrm{C}\right]$ carboxymagnesium halides generated from Grignard reagents and cyclotron-produced $\left[{ }^{11} \mathrm{C}\right] \mathrm{CO}_{2}$, and (ii) an unlabelled amide via microwave-irradiated Grignard coupling reactions (Lu et al., 2003). $N$-(4-Pyridyl)benzamides have been patented as potential cardiotonics (Sakakibara et al., 1987).

For the preparation of (I)-(III), typically, 4-/3-/2-fluorobenzoyl chloride in dry $\mathrm{CH}_{2} \mathrm{Cl}_{2}(20-30 \mathrm{ml})$ was added dropwise (over a period of 2-3 min) to a $20-30 \mathrm{ml}$ solution of 4-aminopyridine containing $\mathrm{Et}_{3} \mathrm{~N}(1.5 \mathrm{ml})$, and the reaction mixture was stirred overnight. Typical organic work-up and washing furnished the products in reasonable yields of $20-40 \%$. Crystals suitable for X-ray diffraction were grown from $\mathrm{CHCl}_{3}$ as colourless blocks over a period of 1-2 weeks.

For (I), m.p. 456-459 K (uncorrected). IR $\left(v_{\mathrm{C}=\mathrm{O}}, \mathrm{cm}^{-1}\right)$ : $1723(s)$, $1682(m)\left(\mathrm{CHCl}_{3}\right) ; 1677(\mathrm{~s})(\mathrm{KBr}) .{ }^{1} \mathrm{H}$ NMR $\left(400 \mathrm{MHz}, \mathrm{CDCl}_{3}\right): \delta$ 8.47 ( $d, 2 \mathrm{H}, 4$-pyr), 8.07 (br s, 1H, N-H), 7.84 ( $m, 2 \mathrm{H}, 4$-Fbenz), 7.54 (d, 2H, 4-pyr), 7.12 ( $m, 2 \mathrm{H}, 4$-Fbenz). For (II), m.p. 443-446 K (uncorrected). IR $\left(v_{\mathrm{C}=\mathrm{O}}, \mathrm{cm}^{-1}\right): 1738(w), 1710(s)\left(\mathrm{CHCl}_{3}\right) ; 1683(s)$ (KBr). ${ }^{1} \mathrm{H}$ NMR (as above): $\delta 8.60$ (d, 2H, 4-pyr), 7.93 (br s, 1H, N$\mathrm{H}), 7.64$ ( $m, 4 \mathrm{H}, 4$-pyr and 3-Fbenz), 7.53 ( $m, 1 \mathrm{H}, 3$-Fbenz), 7.35 ( $m$, 1H, 3-Fbenz). For (III), m.p. 396-398 K (uncorrected). IR $\left(v_{\mathrm{C}=\mathrm{O}}\right.$, $\left.\mathrm{cm}^{-1}\right): 1689(s)\left(\mathrm{CHCl}_{3}\right) ; 1685(s)(\mathrm{KBr}) .{ }^{1} \mathrm{H}$ NMR (as above): $8.66(\mathrm{br}$ $d, 1 \mathrm{H}, \mathrm{N}-\mathrm{H}), 8.57(d, 2 \mathrm{H}, 4-\mathrm{pyr}), 8.17(t, 1 \mathrm{H}, 2-\mathrm{FBenz}), 7.64(m, 2 \mathrm{H}$, 4-pyr), 7.59 ( $m, 1 \mathrm{H}, 2$-Fbenz), 7.36 ( $t, 1 \mathrm{H}, 2$-Fbenz), $7.22(t, 1 \mathrm{H}$, 2-Fbenz).

\section{Isomer (I)}

Crystal data
$\mathrm{C}_{12} \mathrm{H}_{9} \mathrm{FN}_{2} \mathrm{O}$
$M_{r}=216.21$
Monoclinic, $P 2_{1} / c$
$a=5.6506(3) \AA$
$b=11.3882(8) \AA$
$c=15.4314(8) \AA$
$\beta=95.602(3)^{\circ}$

$V=988.27(10) \AA^{3}$

$Z=4$

Mo $K \alpha$ radiation

$\mu=0.11 \mathrm{~mm}^{-1}$

$T=150$ (1) K

$0.26 \times 0.14 \times 0.12 \mathrm{~mm}$ 


\section{organic compounds}

\section{Data collection}

Nonius KappaCCD diffractometer

Absorption correction: multi-scan (SORTAV; Blessing, 1995)

$T_{\min }=0.893, T_{\max }=0.988$

\section{Refinement}

$R\left[F^{2}>2 \sigma\left(F^{2}\right)\right]=0.051$

$w R\left(F^{2}\right)=0.147$

$S=1.03$

2246 reflections

149 parameters

\section{Table 1}

Selected torsion angles $\left({ }^{\circ}\right)$ for $(\mathrm{I})$.

\begin{tabular}{lrrc}
\hline $\mathrm{O} 1-\mathrm{C} 1-\mathrm{N} 1-\mathrm{C} 21$ & $2.5(3)$ & $\mathrm{C} 11-\mathrm{C} 1-\mathrm{N} 1-\mathrm{C} 21$ & $-178.28(16)$ \\
$\mathrm{O} 1-\mathrm{C} 1-\mathrm{C} 11-\mathrm{C} 12$ & $32.0(2)$ & $\mathrm{C} 1-\mathrm{N} 1-\mathrm{C} 21-\mathrm{C} 26$ & $17.7(3)$ \\
\hline
\end{tabular}

Table 2

Hydrogen-bond geometry $\left(\AA,^{\circ}\right)$ for (I).

$C g 1$ is the centroid of the $\mathrm{C} 11-\mathrm{C} 16$ ring.

\begin{tabular}{lllll}
\hline$D-\mathrm{H} \cdots A$ & $D-\mathrm{H}$ & $\mathrm{H} \cdots A$ & $D \cdots A$ & $D-\mathrm{H} \cdots A$ \\
\hline $\mathrm{N} 1-\mathrm{H} 1 \cdots \mathrm{N} 24^{\mathrm{i}}$ & $0.84(2)$ & $2.29(2)$ & $3.022(2)$ & $146(2)$ \\
$\mathrm{C} 26-\mathrm{H} 26 \cdots \mathrm{O} 1$ & 0.95 & 2.32 & $2.878(2)$ & 117 \\
$\mathrm{C} 26-\mathrm{H} 26 \cdots C g 1^{\mathrm{ii}}$ & 0.95 & 2.71 & $3.373(2)$ & 128 \\
\hline
\end{tabular}

Symmetry codes: (i) $-x+1, y+\frac{1}{2},-z+\frac{1}{2}$; (ii) $-x+2,-y,-z+1$.

\section{Isomer (II)}

Crystal data

$\mathrm{C}_{12} \mathrm{H}_{9} \mathrm{FN}_{2} \mathrm{O}$

$M_{r}=216.21$

Monoclinic, $P 2_{1} / c$

$a=5.7537(3) \AA$

$b=11.2421$ (4) $\AA$

$c=15.1672(7) \AA$

$\beta=94.188(2)^{\circ}$

$$
\begin{aligned}
& V=978.45(8) \AA^{3} \\
& Z=4 \\
& \text { Mo } K \alpha \text { radiation } \\
& \mu=0.11 \mathrm{~mm}^{-1} \\
& T=150(2) \mathrm{K} \\
& 0.32 \times 0.20 \times 0.12 \mathrm{~mm}
\end{aligned}
$$

\section{Data collection}

Nonius KappaCCD diffractometer

Absorption correction: multi-scan

(SORTAV; Blessing, 1995)

$T_{\text {min }}=0.801, T_{\max }=0.989$

\section{Refinement}

$R\left[F^{2}>2 \sigma\left(F^{2}\right)\right]=0.048$

$w R\left(F^{2}\right)=0.132$

$S=1.06$

2236 reflections

150 parameters

8753 measured reflections 2236 independent reflections 1474 reflections with $I>2 \sigma(I)$ $R_{\text {int }}=0.054$

Table 3

Selected torsion angles $\left(^{\circ}\right.$ ) for (II).

\begin{tabular}{lrlr}
\hline $\mathrm{O} 1-\mathrm{C} 1-\mathrm{N} 1-\mathrm{C} 21$ & $5.4(3)$ & $\mathrm{C} 11-\mathrm{C} 1-\mathrm{N} 1-\mathrm{C} 21$ & $-175.38(15)$ \\
$\mathrm{O} 1-\mathrm{C} 1-\mathrm{C} 11-\mathrm{C} 12$ & $31.8(2)$ & $\mathrm{C} 1-\mathrm{N} 1-\mathrm{C} 21-\mathrm{C} 26$ & $13.8(3)$ \\
\hline
\end{tabular}

Table 4

Hydrogen-bond geometry $\left(\AA,^{\circ}\right)$ for (II).

$C g 1$ and $C g 2$ are the centroids of the C11-C16 and C21-C23/N24/C25/C26 rings.

\begin{tabular}{lllll}
\hline$D-\mathrm{H} \cdots A$ & $D-\mathrm{H}$ & $\mathrm{H} \cdots A$ & $D \cdots A$ & $D-\mathrm{H} \cdots A$ \\
\hline $\mathrm{N} 1-\mathrm{H} 1 \cdots \mathrm{N} 24^{\mathrm{i}}$ & $0.847(19)$ & $2.30(2)$ & $3.049(2)$ & $147.6(16)$ \\
$\mathrm{C} 26-\mathrm{H} 26 \cdots \mathrm{O} 1$ & 0.95 & 2.31 & $2.884(2)$ & 118 \\
$\mathrm{C} 26-\mathrm{H} 26 \cdots C g 1^{\mathrm{ii}}$ & 0.95 & 2.78 & $3.4407(18)$ & 128 \\
$\mathrm{C} 14-\mathrm{H} 14 \cdots C g 2^{\text {iii }}$ & 0.95 & 2.88 & $3.808(2)$ & 165 \\
$\mathrm{C} 15-\mathrm{H} 15 \cdots C g 2^{\text {iv }}$ & 0.95 & 2.83 & $3.505(2)$ & 129
\end{tabular}

Symmetry codes: (i) $-x+1, y+\frac{1}{2},-z+\frac{1}{2}$; (ii) $-x+2,-y,-z+1$; (iii) $x,-y-\frac{1}{2}, z-\frac{1}{2}$; (iv) $-x+1,-y,-z+1$.

\section{Isomer (III)}

\section{Crystal data}

$\begin{array}{ll}\mathrm{C}_{12} \mathrm{H}_{9} \mathrm{FN}_{2} \mathrm{O} & V=989.80(8) \AA^{3} \\ M_{r}=216.21 & Z=4 \\ \text { Monoclinic, } P 2_{1} / c & \text { Mo } K \alpha \text { radiation } \\ a=5.9832(3) \AA & \mu=0.11 \mathrm{~mm}^{-1} \\ b=11.1508(5) \AA & T=150(2) \mathrm{K} \\ c=14.8921(7) \AA & 0.35 \times 0.30 \times 0.18 \mathrm{~mm}\end{array}$

$\beta=94.986(3)^{\circ}$

\section{Data collection}

Nonius KappaCCD diffractometer 6092 measured reflections Absorption correction: multi-scan 2252 independent reflections (SORTAV; Blessing, 1995) 1744 reflections with $I>2 \sigma(I)$ $T_{\min }=0.911, T_{\max }=0.982 \quad R_{\text {int }}=0.031$

Refinement

$R\left[F^{2}>2 \sigma\left(F^{2}\right)\right]=0.044$

$w R\left(F^{2}\right)=0.121$

$S=1.04$

2252 reflections

149 parameters

$\mathrm{H}$ atoms treated by a mixture of independent and constrained refinement

$\Delta \rho_{\max }=0.18$ e $\AA^{-3}$

$\Delta \rho_{\min }=-0.24 \mathrm{e} \AA^{-3}$

Table 5

Selected torsion angles $\left(^{\circ}\right)$ for (III).

\begin{tabular}{lccc}
\hline $\mathrm{O} 1-\mathrm{C} 1-\mathrm{N} 1-\mathrm{C} 21$ & $6.1(2)$ & $\mathrm{C} 11-\mathrm{C} 1-\mathrm{N} 1-\mathrm{C} 21$ & $-176.77(12)$ \\
$\mathrm{O} 1-\mathrm{C} 1-\mathrm{C} 11-\mathrm{C} 12$ & $-147.55(14)$ & $\mathrm{C} 1-\mathrm{N} 1-\mathrm{C} 21-\mathrm{C} 26$ & $11.2(2)$ \\
\hline
\end{tabular}

Table 6

Hydrogen-bond geometry ( $\AA{ }^{\circ}$ ) for (III).

$C g 1$ and $C g 2$ are the centroids of the C11-C16 and C21-C23/N24/C25/C26 rings.

\begin{tabular}{lllll}
\hline$D-\mathrm{H} \cdots A$ & $D-\mathrm{H}$ & $\mathrm{H} \cdots A$ & $D \cdots A$ & $D-\mathrm{H} \cdots A$ \\
\hline $\mathrm{N} 1-\mathrm{H} 1 \cdots \mathrm{N} 24^{\mathrm{i}}$ & $0.844(19)$ & $2.333(18)$ & $3.0213(17)$ & $139.1(15)$ \\
$\mathrm{N} 1-\mathrm{H} 1 \cdots \mathrm{F} 12$ & $0.844(19)$ & $2.342(17)$ & $2.7544(15)$ & $110.6(14)$ \\
$\mathrm{C} 26-\mathrm{H} 26 \cdots \mathrm{O} 1$ & 0.95 & 2.30 & $2.8681(17)$ & 118 \\
$\mathrm{C} 26-\mathrm{H} 26 \cdots C g 1^{\text {ii }}$ & 0.95 & 2.83 & $3.4549(13)$ & 124 \\
$\mathrm{C} 14-\mathrm{H} 14 \cdots C g 2^{\text {iii }}$ & 0.95 & 2.93 & $3.7693(17)$ & 149 \\
\hline
\end{tabular}

Symmetry codes: (i) $-x+1, y+\frac{1}{2},-z+\frac{1}{2}$; (ii) $-x+2,-y,-z+1$; (iii) $x,-y-\frac{1}{2}$, $z-\frac{1}{2}$.

$\mathrm{H}$ atoms attached to $\mathrm{C}$ atoms were treated as riding using the SHELXL97 (Sheldrick, 2008) defaults at 150 (1) K $[\mathrm{C}-\mathrm{H}=0.95 \AA$ and $U_{\text {iso }}(\mathrm{H})=1.2 U_{\text {eq }}(\mathrm{C})$ ]; $\mathrm{N}$-bound $\mathrm{H}$ atoms were refined freely with isotropic displacement parameters to bond lengths of 0.84 (2) $\AA$ in (I), 0.847 (19) $\AA$ in (II) and 0.844 (19) $\AA$ in (III). 
For all isomers, data collection: KappaCCD Server Software (Nonius, 1997); cell refinement: DENZO-SMN (Otwinowski \& Minor, 1997); data reduction: $D E N Z O-S M N$; program(s) used to solve structure: SHELXS97 (Sheldrick, 2008); program(s) used to refine structure: SHELXL97 (Sheldrick, 2008) and SORTX (McArdle, 1995); molecular graphics: PLATON (Spek, 2003); software used to prepare material for publication: SHELXL97 and PREP8 (Ferguson, 1998).

JFG thanks Dublin City University for funds in aid of undergraduate research and $\mathrm{Mr}$ Damien McGuirk for providing excellent technical and laboratory assistance.

Supplementary data for this paper are available from the IUCr electronic archives (Reference: SK3227). Services for accessing these data are described at the back of the journal.

\section{References}

Allen, F. H., Baalham, C. A., Lommerse, J. P. M. \& Raithby, P. R. (1998). Acta Cryst. B54, 320-329.

Blessing, R. H. (1995). Acta Cryst. A51, 33-38.

Chopra, D. \& Guru Row, T. N. (2008). CrystEngComm, 10, 54-67.

Day, G. M., Motherwell, W. D. S., Ammon, H. L., Boerrigter, S. X. M., Della Valle, R. G., Venuti, E., Dzyabchenko, A., Dunitz, J. D., Schweizer, B., van
Eijck, B. P., Erk, P., Facelli, J. C., Bazterra, V. E., Ferraro, M. B., Hofmann, D. W. M. et al. (2005). Acta Cryst. B61, 511-527.

Dou, S., Weiden, N. \& Weiss, A. (1993). Acta Chim. Acad. Sci. Hung. 130, 497522.

Ferguson, G. (1998). PREP8. University of Guelph, Canada.

Gelbrich, T., Hursthouse, M. B. \& Threlfall, T. L. (2007). Acta Cryst. B63, 621632.

Gilbert, A. S. (2007). Thermochim. Acta, 452, 135-139.

Gowda, B. T., Tokarčík, M., Kožĩšek, J. \& Sowmya, B. P. (2008). Acta Cryst. E64, o83.

Kálmán, A., Párkányi, L. \& Argay, G. (1993). Acta Cryst. B49, 1039-1049.

Lu, S.-Y., Hong, J. \& Pike, V. W. (2003). J. Labelled Compd Radiopharm. 46, 1249-1259.

McArdle, P. (1995). J. Appl. Cryst. 28, 65.

Nonius (1997). KappaCCD Server Software. Windows 3.11 Version. Nonius BV, Delft, The Netherlands.

Otwinowski, Z. \& Minor, W. (1997). Methods in Enzymology, Vol. 276 , Macromolecular Crystallography, Part A, edited by C. W. Carter Jr \& R. M. Sweet, pp. 307-326. New York: Academic Press.

Sakakibara, K., Yoneshima, N. \& Osawa, T. (1987). Jpn Kokai Tokkyo Koho, CODEN JKXXAF JP 62158252 A 19870714 Showa (patent written in Japanese).

Sheldrick, G. M. (2008). Acta Cryst. A64, 112-122.

Slovokhotov, Y. L., Neretin, A. S. \& Howard, J. A. K. (2004). New J. Chem. 28 , 967-979.

Spek, A. L. (2003). J. Appl. Cryst. 36, 7-13.

Wardell, S. M. S. V., de Souza, M. V. N., Vasconcelos, T. R. A., Ferreira, M. L., Wardell, J. L., Low, J. N. \& Glidewell, C. (2008). Acta Cryst. B64, 84-100.

Wardell, S. M. S. V., de Souza, M. V. N., Wardell, J. L., Low, J. N. \& Glidewell, C. (2007). Acta Cryst. B63, 879-895. 